\title{
Passageiros com deficiência visual no transporte aéreo: avaliação da acessibilidade em aeroportos
}

\author{
Talita Naiara Rossi da Silva ${ }^{a}$ (D), Ana Luisa Rodrigues Silva ${ }^{b}$ (D), Valéria Oliveira Caetano ${ }^{b}$ (D), \\ Gabriela Almeida Silvestrini ${ }^{b}$ (D), Nilton Luiz Menegon ${ }^{c}$
}

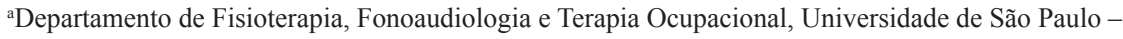

USP, São Paulo, SP, Brasil.

bepartamento de Terapia Ocupacional, Universidade Federal de Minas Gerais - UFMG, Belo Horizonte, MG, Brasil.

'Departamento de Engenharia de Produção, Universidade Federal de São Carlos - UFSCar, São Carlos, SP, Brasil.

\begin{abstract}
Resumo: Introdução: Nas últimas décadas ocorreram mudanças no entendimento da deficiência e avanços no que tange aos direitos humanos das pessoas com deficiência. Apesar disso, estudos mostram que essas pessoas ainda encontram barreiras que restringem sua participação nos diversos contextos sociais, como o transporte aéreo. Objetivo: Analisar as condições e procedimentos de acessibilidade em aeroportos brasileiros e compreender as experiências de viagem de pessoas com deficiência visual nas fases de pré-voo, embarque e desembarque. Método: Pesquisa com abordagem quantitativa-qualitativa realizada a partir de observação participante em viagens aéreas, entrevista de autoconfrontação com passageiros com deficiência visual e verificação do cumprimento das regras sobre condições e procedimentos de acessibilidade por meio de checklists baseados na norma ABNT NBR-9050/2015 e na Resolução ANAC n ${ }^{0}$ 280/2013. Resultados: Participaram do estudo sete passageiros com deficiência visual, incluindo pessoas com cegueira ou com baixa visão, e 30 gerentes de base e supervisores vinculados a quatro companhias aéreas que operam no transporte aéreo doméstico brasileiro. Foram analisados 10 aeroportos, nos quais os passageiros vivenciaram dificuldades que se relacionam, principalmente, a inadequação, descontinuidade e insuficiência das informações e sinalizações, descumprimento e desconhecimento dos procedimentos relativos à acessibilidade, impropriedade da alocação de assentos preferenciais e do atendimento prestado aos passageiros. Conclusão: O estudo evidenciou descumprimento das normas e resoluções relativas à acessibilidade além de problemas que afetam a orientação espacial, o deslocamento e a comunicação nas viagens aéreas. Espera-se contribuir para a transformação da acessibilidade nos aeroportos brasileiros, visando favorecer a participação das pessoas com deficiência nas viagens aéreas.
\end{abstract}

Palavras-chave: Deficiência Visual, Acessibilidade, Aeroporto, Ergonomia, Terapia Ocupacional.

\section{Passengers with visual disability in air transport: evaluation of airports' accessibility}

\begin{abstract}
Introduction: In the last decades, there have been changes in the understanding of disability and advances in the human rights of people with disabilities. Nevertheless, studies show that disabled people still encounter barriers which restrict their participation in various social contexts, such as air transportation. Objective: To analyze accessibility conditions and procedures in Brazilian airports and to understand the travel experiences of people with visual impairment in the pre-flight, embarkation and disembarkation phases. Method: Quantitative-qualitative research based on participant observation in air travel, auto-confrontation interview with visually impaired passengers, and verification of rules compliance of accessibility conditions and procedures through checklists based on ABNT
\end{abstract}

Autor para correspondência: Talita Naiara Rossi da Silva, Universidade de São Paulo, Rua Cipotânea, 51, Cidade Universitária, CEP 05360-000, São Paulo, SP, Brasil, e-mail: talitarossi@usp.br

Recebido em Mar. 13, 2018; $1^{\text {a }}$ Revisão em Out. 9, 2018; Aceito em Mar. 9, 2019. 
NBR-9050/2015 and ANAC Resolution n ${ }^{\circ}$ 280/2013. Results: The participants were seven passengers with visual impairment, either blind or with low vision plus 30 managers and supervisors linked to four different airlines that operate in the Brazilian air transportation. Ten airports were analyzed, in which passengers experienced difficulties related, mainly, to the inadequacy, discontinuity and insufficiency of information and signage; noncompliance with and lack of knowledge of accessibility procedures; inappropriate allocation of preferential seats and attendance to passengers. Conclusion: Besides evidencing the noncompliance with the norms and resolutions related to accessibility, the study also evidenced problems that affect the spatial orientation, the displacement and the communication in travels. Having all this compiled data, contributions to transformation of accessibility in Brazilian airports is expected, with a view to favoring the participation of people with disabilities in air travel.

Keywords: Visual Impairment, Accessibility, Airport, Ergonomics, Occupational Therapy.

\section{Introdução}

A Organização Mundial de Saúde estima que na população mundial cerca de um bilhão de pessoas convivem com alguma forma de deficiência e que a tendência é de aumento desse número nos próximos anos devido ao envelhecimento da população e ao aumento global de doenças crônicas (ORGANIZAÇÃO..., 2011). No Brasil, o Censo Demográfico 2010 apontou que $23,9 \%$ da população, o que corresponde a mais de 45 milhôes de brasileiros, possui pelo menos uma deficiência, sendo que $18,7 \%$ têm deficiência visual, 7,0\% deficiência física, 5,10\% deficiência auditiva e 1,40\% possui deficiência intelectual (BRASIL, 2012).

De acordo com a Organização das Naçôes Unidas (2006, p. 3), entende-se que pessoa com deficiência é

[...] aquela que tem impedimentos de natureza física, intelectual ou sensorial, os quais, em interação com diversas barreiras, podem obstruir sua participação plena e efetiva na sociedade com as demais pessoas.

Essa conceituaçáo, também adotada pela OMS na Classificaçáo Internacional de Funcionalidade, Incapacidade e Saúde, enfatiza que a funcionalidade e a incapacidade humanas resultam da interação entre um indivíduo com determinada condição de saúde e os fatores contextuais, que incluem fatores pessoais e ambientais. Logo, a realização de atividades e a participação não são determinadas unicamente por características individuais, mas também por fatores sociais e ambientais (ORGANIZAÇÃO..., 2008; SAMPAIO; LUZ, 2009).

Com relação à deficiência visual, estima-se que, mundialmente, 36 milhóes de pessoas têm cegueira, mais de 216 milhóes possuem deficiência visual moderada a grave e cerca de 188 milhóes têm comprometimento visual leve (BOURNE et al., 2017). Pessoas idosas e com piores condiçóes socioeconômicas apresentam maiores índices de deficiência visual. Em 2010, 82\% das pessoas cegas e 65\% daquelas que tinham deficiência visual moderada a grave tinham 50 anos ou mais (WORLD..., 2013). Essa deficiência está relacionada a condiçôes do sistema visual e refere-se a déficits na capacidade óptica que afetam a percepção das informaçóes ambientais visuais. Consequentemente, pode comprometer a realização de atividades cotidianas, tais como leitura, orientação e mobilidade (WORLD..., 2018).

No Brasil, o Decreto no 5296 de 02 de dezembro de 2004 define dois tipos de deficiência visual: cegueira e baixa visão.

A cegueira é caracterizada por acuidade visual ${ }^{1}$ igual ou menor que 0,05 no melhor olho, com a melhor correção óptica. A baixa visão significa acuidade visual entre 0,3 e 0,05 no melhor olho, com a melhor correçáo óptica; e os casos nos quais a somatória da medida do campo visual em ambos os olhos for igual ou menor que $60^{\circ}$ ou a ocorrência simultânea de quaisquer das condiçóes anteriores (BRASIL, 2004).

$\mathrm{Na}$ deficiência visual, a alteração da visão em graus variáveis limita as possibilidades de percepção e apreensão do mundo externo (AMIRALIAN, 1997, 2004). No entanto, cabe salientar que limitações variam não só em relaçáo à acuidade visual, mas, também, em relação ao campo visual, à sensibilidade aos contrastes, à adaptação à luz e ao escuro, à percepção de cores e, principalmente, à eficácia no uso da visão. Além disso, as experiências vividas no cotidiano serão influenciadas também por fatores sociais e ambientais, não apenas com as capacidades individuais (AMIRALIAN, 2004).

Para obter informaçóes do ambiente e conseguir orientar-se no espaço, as pessoas com deficiência visual fazem uso dos demais sistemas perceptivos (audição, háptico, paladar, olfato) e utilizam equipamentos, técnicas e métodos específicos, por exemplo, a 'bengala branca', o 'cão-guia' e as informaçôes sonoras. Para leitura e escrita podem utilizar, por exemplo, o método Braille ou programas computacionais 
sonoros para leitura de telas (DISCHINGER; ELY; PIARDI, 2012).

Apesar dos avanços no entendimento da deficiência e no desenvolvimento da tecnologia assistiva, estudos apontam que as pessoas com deficiência ainda vivenciam limitações nas atividades e restrições à participação nos diferentes contextos sociais. No transporte aéreo, por exemplo, diversos autores identificaram barreiras que dificultam as viagens aéreas em todas as suas fases: pré-viagem (planejamento e reservas), pré-voo (aeroporto), embarque, voo e desembarque (SILVA et al., 2017; SILVA, 2016; CHANG; CHEN, 2012; DARCY, 2012; SMALL; DARCY; PACKER, 2012; PORIA; REICHEL; BRANDT, 2010).

Small, Darcy e Packer (2012) e Poria, Reichel e Brandt (2010) ressaltaram que, nas experiências de viagens de pessoas com deficiência visual, são observadas barreiras no acesso a informação ou a localização e orientação nos terminais aeroportuários. Além disso, os passageiros com deficiência visual sentem-se inseguros em relação à escuta e compreensão dos avisos sonoros, devido ao ambiente ruidoso do aeroporto e a não familiaridade com as orientaçôes de segurança fornecidas pelos comissários de bordo na aeronave. Em estudo desenvolvido no transporte aéreo brasileiro, o formato, a qualidade e o conteúdo das informaçóes e sinalizações nos aeroportos e aeronaves também foram apontados como barreiras nas viagens de passageiros com deficiência visual (SILVA et al., 2017). Outra barreira é o desconhecimento dos prestadores de serviço quanto às regras para a viagem com cão-guia e a falta de espaços para acomodação do animal junto ao passageiro na aeronave (SMALL; DARCY; PACKER, 2012).

Na cabine das aeronaves a atitude dos comissários de bordo pode constituir uma barreira quando os tripulantes se dirigem aos acompanhantes dos passageiros com deficiência visual para tratar assuntos de interesse desses últimos. Por vezes, oferecem um tratamento infantilizado ou falam mais alto e lentamente, como se esses passageiros não ouvissem ou não compreendessem o que é falado, não olhando-os diretamente durante a interação (PORIA; REICHEL; BRANDT, 2010). Além disso, os sistemas de entretenimento a bordo não são acessíveis às pessoas cegas e com baixa visão, o que torna necessário a incorporação de recursos para atender a diversidade de passageiros, incluindo aqueles com deficiências sensoriais (SILVA, 2016), tais como leitores de tela e audiodescrição dos conteúdos.

Tendo em vista o exposto, essa pesquisa teve como objetivo analisar as condiçôes e procedimentos de acessibilidade em aeroportos brasileiros e compreender as experiências de viagem de pessoas com deficiência visual nas fases de pré-voo, embarque e desembarque.

\section{Método}

Esse estudo foi desenvolvido no âmbito do Projeto Universalidade: compreender para melhorar, o qual foi realizado por meio de uma parceria entre a Universidade Federal de São Carlos (UFSCar), a Universidade Federal de Minas Gerais (UFMG) e a Agência Nacional de Aviação Civil (ANAC). Fundamentou-se na abordagem quantitativa-qualitativa e no método da Análise Ergonômica do Trabalho, o qual preconiza a análise em situaçóes reais e o envolvimento de diferentes sujeitos (GUÉRIN et al., 2001). O estudo foi aprovado pelo Comitê de Ética em Pesquisa envolvendo Seres Humanos (CAAE: 18017613.7.0000.5504).

\subsection{Participantes e local da pesquisa}

Participaram da pesquisa pessoas com deficiência visual (cegueira e baixa visão), usuárias ou não do transporte aéreo, maiores de 18 anos e independentes para realização de viagens. Os participantes foram selecionados a partir da divulgação da pesquisa junto à comunidade da UFMG e às pessoas cadastradas no banco de contatos elaborado no Projeto Cabine Universal: compreendendo as necessidades especiais de usuários do transporte aéreo, desenvolvido entre 2012 e 2014 pela UFSCar e a Embraer S/A. A coleta de dados foi realizada entre março e dezembro de 2016. Gerentes de base e supervisores das companhias aéreas que operam nos aeroportos analisados também participaram do estudo fornecendo informaçóes acerca dos procedimentos da companhia em determinado aeroporto em relação a Resolução da ANAC no 280/2013.

Em relação ao local da pesquisa, foram incluídos os aeroportos que compuseram as viagens realizadas pelos participantes, os quais são localizados em quatro regiôes brasileiras: sul, sudeste, norte e nordeste.

\subsection{Procedimentos e instrumentos para coleta de dados}

A verificação das condiçóes de acessibilidade foi realizada por meio de observação sistemática nos terminais pelos pesquisadores, utilizando um checklist criado a partir da norma ABNT NBR-9050/2015. A referida norma estabelece critérios e parâmetros técnicos a serem observados no projeto, construçáo, instalaçáo e adaptação do meio urbano e rural, e de edificaçôes às condiçóes de acessibilidade. 
Em relação às pessoas com deficiência visual, essa norma determina, por exemplo, que portas e passagens devem possuir informaçôes visuais associadas a sinalização tátil e sonora; painéis de chamada de elevadores e plataformas elevatórias devem ter informaçôes em relevo e em Braille; percursos devem possuir sinalização tátil e visual de alerta e direcional no piso.

A verificação dos procedimentos relativos à acessibilidade foi realizada por meio de entrevistas estruturadas com os gerentes e supervisores de base das companhias aéreas que operam nos aeroportos analisados. Para tanto, utilizou-se um checklist elaborado pelos pesquisadores a partir da Resolução ANAC no 280/2013, o qual foi constituído apenas por questôes relativas aos procedimentos necessários para transporte adequado dos passageiros com necessidade de assistência especial (PNAE), incluindo as pessoas com deficiência. O Art. 14 item XII da Resolução, por exemplo, estabelece que deve ser realizada a demonstração individual dos procedimentos de emergência quando solicitado pelo PNAE (AGÊNCIA..., 2013).

Para compreensão das experiências no transporte aéreo, pessoas com deficiência visual foram acompanhadas ao longo do o ciclo de viagem (pré-voo, embarque e desembarque da aeronave) e foram utilizados como procedimentos para coleta de dados observação participante (MINAYO, 2010) e entrevistas de autoconfrontação (GUÉRIN et al., 2001). As observaçôes foram registradas por meio de vídeos, imagens e relatos em áudio. Nas entrevistas o pesquisador assistiu aos vídeos com o participante e realizou a descrição do conteúdo. Para guiar as entrevistas foi utilizado um roteiro com perguntas abertas sobre a experiência de viagem, barreiras e facilitadores.

\subsection{Procedimentos para análise de dados}

Os dados das verificaçôes das condições e procedimentos de acessibilidade foram organizados em uma única planilha para análise descritiva das adequaçôes e inadequaçôes em relação ao estabelecido na norma e resolução consideradas. As entrevistas com passageiros foram transcritas e analisadas de acordo com a técnica de análise de conteúdo temática. Foram realizadas leituras flutuantes e exploratórias dos dados, exploração do material para identificação de temas e formação de categorias analíticas e, finalmente, análise e interpretação dos resultados obtidos (MINAYO, 2010). As filmagens das viagens dos passageiros foram assistidas pelas pesquisadoras para análise da atividade, nas quais foram descritas as ações realizadas, as verbalizaçôes, as estratégias e dificuldades encontradas. Essas informaçóes foram complementadas por outros registros de observaçáo.

Os resultados foram discutidos em relação ao conceito de acessibilidade espacial que define um conjunto de diretrizes e características espaciais a fim de permitir a acessibilidade nos edifícios públicos e minimizar possíveis restrições à participação. $\mathrm{O}$ conceito compreende a possibilidade de acesso aos mais variados lugares e atividades, como também o uso de seus equipamentos de maneira independente. Apesar de dividido em quatro componentes - orientação espacial, comunicação, deslocamento e uso - ressalta-se que todos devem ser atendidos em sua totalidade para a construção de espaços acessíveis (DISCHINGER; ELY; PIARDI, 2012).

\section{Resultados}

Os resultados apresentam primeiramente a caracterização dos participantes, os aeroportos analisados e, em seguida, as categorias analíticas: Orientação espacial nos aeroportos: informação e sinalização; Procedimentos relativos à acessibilidade: descumprimento e desconhecimento do prescrito (Resolução ANAC no 280/2013); Alocação de assentos preferenciais: negociaçóes entre os direitos, necessidades e interesses comerciais; Atendimento prestado ao passageiro: dificuldades para comunicação e compreensão das necessidades dos grupos. Os resultados das verificaçóes das condiçóes e procedimentos de acessibilidade são apresentados de modo articulado ao conteúdo de cada categoria.

\subsection{Participantes e aeroportos analisados}

Participaram do estudo sete passageiros com deficiência visual, incluindo pessoas com cegueira ou com baixa visão. Em relação ao hábito de viajar, dois dos participantes não haviam viajado de avião, dois viajavam de avião 1 ou 2 vezes ao ano e os outros três participantes utilizavam o transporte aéreo menos de uma vez ao ano, de 3 a 5 vezes ao ano ou mais de 5 vezes ao ano. A Tabela 1 apresenta a caracterização dos participantes e os 10 aeroportos analisados.

Além dos passageiros, participaram do estudo 30 gerentes de base e supervisores vinculados a quatro companhias aéreas que operam no transporte aéreo doméstico brasileiro e nos aeroportos incluídos nesse estudo. 
Tabela 1. Caracterização dos passageiros participantes e aeroportos analisados.

\begin{tabular}{|c|c|c|c|c|c|c|}
\hline Passageiro & Sexo & Idade & Escolaridade & $\begin{array}{c}\text { Tipo de } \\
\text { deficiência } \\
\text { visual }\end{array}$ & $\begin{array}{l}\text { Dispositivo } \\
\text { assistivo } \\
\text { utilizado }\end{array}$ & $\begin{array}{c}\text { Aeroportos/Trecho } \\
\text { de Viagem }\end{array}$ \\
\hline P1 & Feminino & 28 & $\begin{array}{l}\text { Ensino médio } \\
\text { completo }\end{array}$ & Cegueira & Bengala & $\begin{array}{l}\text { Campinas / } \\
\text { Viracopos - } \\
\text { Florianópolis }\end{array}$ \\
\hline P2 & Masculino & 41 & $\begin{array}{l}\text { Ensino superior } \\
\text { completo }\end{array}$ & Cegueira & Cão guia & $\begin{array}{l}\text { São Paulo/ Cumbica } \\
\text { - Aracajú }\end{array}$ \\
\hline P3 & Masculino & 29 & $\begin{array}{l}\text { Ensino superior } \\
\text { incompleto }\end{array}$ & Baixa Visão & $\begin{array}{l}\text { Leitor de tela para } \\
\text { celular }\end{array}$ & $\begin{array}{l}\text { Belo Horizonte/ } \\
\text { Confins - Rio de } \\
\text { Janeiro/ Galeão }\end{array}$ \\
\hline P4 & Masculino & 55 & $\begin{array}{l}\text { Ensino médio } \\
\text { completo }\end{array}$ & Baixa Visão & Bengala & $\begin{array}{l}\text { São Paulo/ Cumbica } \\
\text { - Aracajú }\end{array}$ \\
\hline P5 & Feminino & 34 & $\begin{array}{l}\text { Ensino superior } \\
\text { completo }\end{array}$ & Cegueira & Bengala & $\begin{array}{l}\text { Belo Horizonte/ } \\
\text { Confins - Rio de } \\
\text { Janeiro/ Galeão - } \\
\text { Porto Alegre }\end{array}$ \\
\hline P6 & Feminino & 27 & $\begin{array}{l}\text { Ensino superior } \\
\text { completo }\end{array}$ & Baixa Visão & Lupa de mão & $\begin{array}{l}\text { Belo Horizonte/ } \\
\text { Confins -São Paulo/ } \\
\text { Congonhas }\end{array}$ \\
\hline P7 & Feminino & 44 & $\begin{array}{l}\text { Ensino superior } \\
\text { completo }\end{array}$ & Cegueira & Bengala & $\begin{array}{l}\text { Campinas/Viracopos } \\
\text { - Belém - Macapá }\end{array}$ \\
\hline
\end{tabular}

Fonte: Elaborado pelos autores.

\subsection{Orientação espacial nos aeroportos: informação e sinalização}

Essa primeira categoria analítica foi dividida em quatro subcategorias: Ausência ou inadequação das orientaçóes e informaçôes na chegada ao aeroporto; Inadequação da sinalização em escadas, rampas e pontes de embarque/desembarque; Inadequação, ausência e descontinuidade da sinalização no terminal; Inexistência ou desatualização de cardápio em Braille em restaurantes, lanchonetes e similares.

\subsubsection{Ausência ou inadequação das orientações e informações na chegada ao aeroporto}

Considerando as necessidades dos passageiros com deficiência visual, as dificuldades podem iniciar logo na chegada ao aeroporto, como relata o participante P4 ao realizar sua primeira viagem aérea.

$E$ É, minha dificuldade é como eu estava sozinho era na hora de descer do táxi para entrar no aeroporto, por que não tem assim um monitoramento de câmera para alguém ver e falar "olha, tem um deficiente visual sozinho lá na entrada do portão, entendeu?" e eu acho que faltou isso aí. Quando eu parei náo deu 2 minutos ou 3 minutos ai veio uma pessoa "Você precisa de ajuda e tal?" ai eu falei "Ah eu preciso de ajuda pra vê se acho um segurança, alguém assim pra me levar até o checkin, eu preciso fazer o check-in lá na companhia" aí ele "Não, eu vou com você lá" aí ele me levou até lá. Podia ter uma ajuda própria do aeroporto, uma pessoa especifica para ficar lá no monitor ou então um sistema que quando um deficiente chega sozinho no aeroporto ele achar tipo assim, uma campainha, um lugar que tenha um sistema para tipo assim, quando eu chego do aeroporto do táxi ou sei lá, alguém me leva lá eu peço "me deixa assim, onde tem, sei lá, um sistema de som, tocar uma campainha, vai acionar alguém lá dentro e eles vão falar, vão ver pela câmera e falar "Vixe, tem um deficiente precisando de ajuda e tá lá no portão, entendeu?" ai avisa "oh aguarda aí que já está indo alguém ai para auxiliar" (Participante P4; Aeroporto de São Paulo/Guarulhos).

Além de não haver um sistema para solicitar ajuda na chegada ao aeroporto, verificou-se que em seis dos terminais avaliados inexistem planos e mapas táteis para orientação espacial nos terminais, a saber: Aracajú, Belo Horizonte/Confins, Campinas/Viracopos, Florianópolis Rio de Janeiro/Galeão, São Paulo/Congonhas. Nesses três últimos, as informaçóes disponibilizadas no balcão de informação não estão em formatos acessíveis (mínimo em dois formatos), conforme estabelece a ABNT NBR 9050/2015 (ASSOCIAÇÃO..., 2015). 


\subsubsection{Inadequação da sinalização em escadas, rampas e pontes de embarque/desembarque}

Em relação às escadas e rampas, os aeroportos de Aracajú, Belo Horizonte/Confins e Macapá não atendem a recomendação quanto à sinalização tátil-visual no início e fim do corrimão para comunicar o pavimento. Ademais, nesses dois últimos e no aeroporto de Florianópolis não há faixa de sinalização contrastante nos degraus das escadas, conforme relatou um dos participantes.

É dificil, por exemplo, as escadas pra acessar certos lugares nos terminais. Algumas são escadas rolantes então não tem tanto problema, mas mesmo assim eu não vejo quando o corrimão tá parado ou não, então às vezes minha mão vai e eu não vou, e eu quase caio da escada rolante. As escadas normais, se elas náo tiverem o piso que mostra onde acaba o andar também eu machuco bastante. Tem certos lugares do aeroporto, elevaçóes que tem no piso que não são sinalizadas, e aí eu acabo tropeçando também. E as esteiras, que são as esteiras retas de levar mala, eu não consigo perceber se elas estão paradas, se estão andando, e ai eu acabo tropeçando também, bastante (Participante P6).

Os passageiros participantes mencionaram também dificuldades relacionadas à falta de sinalização nas pontes de embarque/desembarque e nas escadas utilizadas para embarque e desembarque remotos.

No finger [ponte que conecta com a aeronave para embarque e desembarque] também, porque ele não tem sinalização nenhuma. Então eu não vejo quando ele tá subindo ou descendo, quando vejo ele já está abaixando, tem rampa, e ai também dá pra tropeçar (Participante P6).

Essas escadas [escadas móveis utilizadas no embarque/desembarque] com vazado éperigoso tanto pra pessoas deficientes que ele pode encostar o pé ali na frente pra subir no degrau na vazada (Participante P2).

Aquela descida, quando a gente desce pela porta traseira também, a escada é toda de aluminio, então quando eu olho assim pra baixo parece que é uma rampa [não há sinalização nos degraus]. Eu desci bem devagarzinho e ela balançava muito. Eu ia deslizando com o pé até achar o final dela e ia devagarzinho (Participante $\mathrm{P} 6$ ).

\subsubsection{Inadequação, ausência e descontinuidade da sinalização no terminal}

Nos aeroportos brasileiros a sinalização para indicar espaço, informar direção, sinalizar risco e outras informaçóes é principalmente visual e não é associada a outros formatos, como tátil ou sonoro, o qual é utilizado principalmente para avisos de voos. Tais avisos, juntamente com o elevado número de pessoas no terminal, podem gerar excesso de ruídos e confusão para orientação, conforme exemplificado no relato de um dos entrevistados.

Pra quem tem deficiência visual, o aeroporto dá certa afliçáo porque é muita gente, de todo o lado, de todo lugar, e ninguém tem dó não, eles vão levando a gente com mala e tudo, você sai machucado e ninguém tem dó, é terrivel. E por a gente escutar um pouco mais, a gente vai escutando voz de tudo quanto é lugar, vai escutando voo chamar, e ai você não consegue perceber que seu voo tá sendo chamado, e você precisa ir pra área de embarque, e não sabe qual que é a área de embarque, e aí você pergunta pra pessoa e vai dando uma aflição (Participante P6).

Em outro relato, verificou-se que a sinalização em Braille na botoeira e anúncios verbais não foram identificados nos elevadores do aeroporto de Aracajú. $\mathrm{Na}$ sinalização visual foram referidos e observados problemas relativos ao baixo contraste entre as cores utilizadas nas placas, por exemplo, cinza ou branco e azul ou cinza e amarelo; além de letras pequenas, excesso de informaçóes e placas ou painéis muito altos, dificultando a visualização.

Todas as viagens aéreas que eu fiz tinham que ser acompanhadas de alguém, pra me ajudar a achar check-in, porque a maioria dos check-ins não têm contraste, esse tipo de coisa que me ajuda a identificar o local. Achar também o local de embarque tem que ser acompanhada de alguém, ou eu tenho que fazer isso com 2 ou 3 horas de antecedência pra eu ir olhando as placas. O embarque também é bem complicado, eu sempre pergunto às pessoas, porque é muito dificil de achar de primeira, as placas são muito altas. O painel de voo não tem contraste, as letras são pequenas, são muito altas, não tem como eu ver, então tenho que perguntar pra alguém sempre, quem eu acho na frente eu sempre pergunto (Participante P6).

Sobre a sinalização tátil-visual de alerta e direcional no piso, esta não está disponível em todos os aeroportos e, quando existente, está instalada inadequadamente, por exemplo, não conecta com 
as principais funçôes do terminal, é descontinuada ou possui obstáculos no percurso. Vale salientar a necessidade de associação do piso tátil ao mapa tátil para que o usuário saiba para onde irá ao seguir pelo percurso. Falas de passageiros exemplificam as dificuldades decorrentes da ausência ou inadequação da sinalização tátil-visual nos pisos dos aeroportos.

Enquanto deficiente visual o aeroporto de Confins não atende, não me atende, ele não tem piso tátil, ele não term uma acessibilidade fácil e ele não me direciona. Se não tiver alguém me auxiliando é impossivel uma locomoção com liberdade e autonomia em Confins (Participante P5).

[No aeroporto de] Guarulhos a acessibilidade tem piso tátil em alguns locais e outros não, é descontínuo. Então não é suficiente, porque o ideal é que tenha todas as companhias tenha, ao longo de todo o aeroporto tenha o piso tátil, nos banheiros, me dê a liberdade para eu me expressar da forma que eu desejar, sozinha, independente, $e$ com autonomia. E esse o aeroporto de Guarulhos alguns trechos tinha e outros não, assim como Galeão e aqui em Porto Alegre (Participante P5).

\subsubsection{Inexistência ou desatualização de cardápio em Braille em restaurantes, lanchonetes e similares}

Nas lanchonetes e restaurantes dos aeroportos de Florianópolis, Macapá, Porto Alegre, São Paulo/Congonhas e Cumbica não são disponibilizados cardápios em Braille. Nos demais aeroportos analisados, apesar de existirem cardápios no referido formato, os mesmos não estavam atualizados.

\subsection{Procedimentos relativos à acessibilidade: descumprimento e desconhecimento da Resolução ANAC n ${ }^{\circ} 280 / 2013$}

A partir da verificação com o checklist da Resolução ANAC no 280/2013 constatou-se que diversos procedimentos relativos a acessibilidade não são cumpridos. Nesse sentido, de acordo com $53 \%$ dos respondentes, os quais trabalham para uma das quatro companhias aéreas incluídas no estudo em 9 dos 10 terminais analisados, não é realizado registro de PNAE com condição estável. Além disso, $56 \%$ dos participantes, incluindo todos os aeroportos analisados, informaram que não há sistema de controle de qualidade de atendimento de PNAEs. Outros procedimentos que se destacam pelo descumprimento em 8 dos aeroportos visitados foram: oferecimento de desconto para assentos adicionais caso o PNAE necessite, o qual não é praticado segundo $43 \%$ dos gerentes/supervisores e; profissional responsável por acessibilidade, o qual é inexistente nas companhias aéreas e aeroportos conforme afirmaram $40 \%$ dos participantes. Com relação ao oferecimento de acompanhante para PNAEs com condições de saúde específicas, $40 \%$ dos respondentes mencionaram que a companhia não possui esse serviço.

Pedi pra eles chamarem a pessoa, por que todo aeroporto é obrigado a ter 24 horas uma pessoa que eles chamam especializada em caso de inclusão e acessibilidade. Isso é obrigatório, tá na norma [Resoluçáo ANAC no 280/2013], não chamaram não sabiam dessa questão (Participante P2).

De acordo com os entrevistados, os procedimentos que interferem mais especificamente na experiência de passageiros com deficiência visual são atendidos por todas as companhias aéreas nos aeroportos analisados, por exemplo, permissão para que o passageiro com cegueira viaje com cão guia e assistência durante todo o ciclo de viagem. Entretanto, as observaçóes e entrevistas com passageiros com deficiência visual revelaram algumas contradiçóes, como a não realização do check-in pela companhia aérea logo que uma passageira chegou ao aeroporto de Porto Alegre com mais de 2 horas de antecedência para o voo, visando retardar o início da assistência à passageira e; dificuldades no check-in e na passagem por procedimentos de segurança utilizando recursos de tecnologia assistiva, em especial, o cáo-guia.

Aqui a moça da companhia não nos recebeu, não nos orientou, ela só falou que o check-in é só duas horas antes do voo, não deu assim direcionamento pra nós. Desde o início eu senti um distanciamento, certa resistência (Participante P5).

[Outra] É a questão do atestado. O que a Lei fala, a Lei diz que tem que trazer a carteira de formação do cão e fala que você tem que trazer também a carteira de vacinação autorizada, só que eles pedem um atestado de 10 dias e a Lei de cão guia não fala desse atestado. Ai o que eles falam: é uma norma da empresa e uma norma da ANVISA, só que a norma da empresa e a norma da ANVISA não podem ser superiores a legislação, se na Lei não fala, você não pode ter uma norma que pede mais que a Lei. É uma coisa de louco por que às vezes eles não pedem nada, nem a carteira. Então o procedimento é muito... não tem muito 
padrão, não tem procedimento. Às vezes pedem todos os documentos e às vezes não pedem nada (Participante P2).

Ele poderia ter feito uma busca no equipamento do cão, não haveria problema. O que não poderia ser feito é que geralmente eles pedem pra fazer e ai estão pedindo é pra tirar o equipamento, porque novamente a Lei não fala isso, inclusive ela fala que não pode ser causado qualquer obstáculo. Não vai tirar. Ele é obrigado a se submeter à inspeção e eu nunca me neguei a fazer isso, sem problema, agora eu não posso deixar o cão sem equipamento por que o comportamento dele muda um pouco, pessoas podem se assustar e se a Norma fala que a bordo o cáo term que ficar com os equipamentos porque que fora não? Ele tem que tá com a guia (Participante P2).

E na detecção de metal eles não sabiam como agir, não sabia direito como agir e eu falei que seria interessante eu passar com o cão, solta-lo ali e falei que era pra fazer a inspeção manual, falei para ele fazer em mim e no cachorro também (Participante P2).

No embarque, uma dificuldade identificada refere-se às mudanças de portão, conforme mencionado pela participante P6.

Várias vezes eu passei por essa experiência do portão mudar, eu dentro do aeroporto e o portáo mudar por falta de finger, essas coisas, e eu fico sem saber. Ai eu chego no meu portão, que tá no meu cartão de embarque. Porque por exemplo, quando eu faço check-in eu pergunto pra pessoa qual é meu portão de embarque, ai desse caminho até lá o portão já mudou e eu não fico sabendo porque eu náo consigo ler na placa (Participante P6).

\subsection{Alocação de assentos preferenciais: negociações entre direitos, necessidades e interesses comerciais}

Outras dificuldades vivenciadas pelos passageiros participantes relacionam-se a acomodação na cabine, especificamente à alocação de assentos próximos à janela ou os preferenciais que também são comercializados como assentos 'conforto', por estarem em fileiras que disponibilizam maior espaço para as pernas.

A dificuldade no assento, você tem que explicar que você náo pode ir no corredor e nem no meio porque eu indo pro assento de corredor vou atrapalhar o serviço de bordo e se duas pessoas estiverem do meu lado e eu vou atrapalhar as pessoas passarem e sairem para ir ao banheiro também com o cão no serviço de bordo, ele pode ficar com a patinha no corredor ou o rabo. E é uma questão bem clara essa. E você muitas vezes, você não consegue mudar no check-in, então eles pedem pra mudar a bordo e aí você tem toda a tensão. É pra mim e pra pessoa. Ela comprou, se comprou ela tem direito, mas também envolve uma questão legal e dí? (Participante P2).

\subsection{Atendimento prestado ao passageiro: dificuldades para comunicação e compreensão das necessidades dos grupos}

Por fim, os passageiros participantes do estudo relataram dificuldades com o atendimento prestado pelas companhias aéreas, em especial, para comunicação com funcionários ao efetuar o check-in e no processo de embarque. Além disso, mencionaram o desconhecimento por parte dos atendentes sobre as necessidades dos diferentes grupos compreendidos como PNAEs e a demora nos procedimentos de desembarque.

Não gostei do check-in. As pessoas têm muita dificuldade, em todas elas percebi isso, dificuldade de abordar, de como proceder com o deficiente visual, pra isso você tem treinamento né, como você dá o braço, como vocêse porta em lugar estreito, em lugar aberto assim. Eu senti um despreparo geral assim. Não tô falando de boa vontade agora, tô falando de capacitação. Todos do inicio ao fim precisam melhorar né assim em questão de deficiente visual, em relação a minha deficiência, eles podem fazer melhor (Participante P5).

Eu acho que na hora de receber o cartão de embarque, eu não lembro se ela falou do cartão de embarque para mim. Ela só falou para segurar aquele papelzinho. Entäo mas a gente fica pensando que será que tem nesse papelzinho. Ah faltou [comunicação], por exemplo, conta esses detalhes né. Por exemplo, por que a pessoa que enxerga já sabe que aquilo ali é o cartão de embarque essas coisas assim né a gente não, então teria que descrever né (Participante P1).

Uma vez uma coisa também que eu achei muito louca, eu não me lembro que aeroporto foi, ah foi Congonhas, eles me colocaram junto no ambulift. É complicado porque, assim, sobe e desce e nivela e não havia necessidade disso aí você vai e explica e eles falam "não, espera que ai vai todo mundo junto" e dá pra ir no ônibus, por exemplo, não 
tem alguém pra levar da aeronave até o ônibus, tudo bem, se alguém na remota me colocar no ônibus, mesmo de bordo e avisar a viagem que vai desembarcar e alguém tiver me esperando na descida do ônibus, também dá pra fazer (Participante P2).

Parece que, assim, a pessoa com deficiência visual acho que pega muito por que perde o contato visual parece que as pessoas não ouvem você (Participante P2).

Eu já fiquei esperando a última pessoa desembarcar pra eu desembarcar e o último passageiro desembarcou e eu fiquei mais 10 minutos, 15 , esperando alguém vir me buscar na remota e ai eu esperando na aeronave e a moça limpando o banheiro, limpando o chão (Participante P2).

\section{Discussão}

Os resultados dessa pesquisa mostraram que os passageiros com deficiência visual vivenciam dificuldades nas viagens aéreas as quais são determinadas por problemas relativos às condiçôes e procedimentos de acessibilidade, assim como, por questóes relacionadas ao atendimento prestado pelas companhias aéreas, incluindo as políticas de comercialização de assentos considerados preferenciais.

Em relação às condições de acessibilidade, foram verificadas dificuldades na chegada aos aeroportos, por exemplo, devido à falta de um sistema para solicitar ajuda na entrada do terminal, inexistência de planos e mapas táteis na maioria dos aeroportos e informaçôes prioritariamente em formato visual. Com relação às placas e painéis de informaçóes foi observado o baixo contraste entre as cores utilizadas, letras pequenas, excesso de informações e posicionamento muito elevado, dificultando a visualização.

Nas escadas fixas e móveis, as quais são utilizadas nos embarques e desembarques remotos, há inadequaçóes na sinalização nos corrimãos e nos degraus, o que pode prejudicar a orientaçáo em relação aos pavimentos do terminal, como também aumentar o risco de quedas. Outro problema constatado foi a ausência, descontinuidade ou inadequação da sinalização tátil-visual nos pisos dos aeroportos.

As questóes relacionadas à falta de informaçóes em formatos acessíveis, a insegurança em relação aos anúncios sonoros de voos e a dificuldade para localização nos aeroportos também foram apontados por participantes dos estudos de Poria, Reichel e Brandt (2010); Small, Darcy e Packer (2012) e Silva (2016).

Conforme salientaram Gomes e Emmel (2016), para a percepção e estruturação mental dos espaços é fundamental a sensação produzida pelos sentidos, principalmente a visão, responsável pelo primeiro impacto criador de significados do ambiente. Desse modo, é necessário que os espaços disponibilizem equipamentos e outros elementos que favoreçam a interação com o meio a partir dos vários sentidos, favorecendo a participação da pessoa com deficiência visual.

Os problemas nas condiçóes de acessibilidade identificados afetam, principalmente, a 'orientação espacial' e o 'deslocamento' nos terminais analisados, conforme conceito de acessibilidade espacial proposto por Dischinger, Ely e Piardi (2012). Tais circunstâncias levam a necessidade de auxílio e guia por outras pessoas, conforme também destacado por Poria, Reichel e Brandt (2010). Além disso, verificaram-se prejuízos ao componente 'comunicaçáo' na ausência ou desatualização dos cardápios em Braille nas lanchonetes e restaurantes dos aeroportos.

No que se refere aos procedimentos de acessibilidade, constatou-se o descumprimento de itens estabelecidos na Resolução ANAC no 280/2013, por exemplo, em relação a assistência em todas as fases da viagem, utilizando-se de estratégias para adiar o início do auxílio ao passageiro, e dificuldades nos procedimentos de segurança acompanhado por cão-guia. Problemas no embarque e desembarque foram evidenciados, com destaque para a mudança de portáo de embarque sem avisos em formatos acessíveis, acomodaçáo na cabine devido a conflitos na alocação de assentos em posiçóes preferenciais, e demora nos procedimentos para sair da aeronave. Esse último problema, foi apontado no estudo de Silva (2016), juntamente com a falta de condiçóes adequadas para desembarque, devido ao uso de escadas na remota e a falta de sinalização nas pontes de embarque/desembarque.

Os resultados ressaltaram ainda dificuldades geradas pelo atendimento aos passageiros, em especial, devido ao desconhecimento por parte dos atendentes sobre as necessidades dos diferentes grupos compreendidos como PNAEs e às condutas inapropriadas nas interaçôes no check-in e no processo de embarque. Por vezes, os participantes consideraram que o tratamento oferecido foi infantilizado ou então direcionado ao acompanhante mesmo quando se tratavam de questôes relacionadas ao PNAE, como 
também apontado por Poria, Reichel e Brandt (2010) e Silva (2016). Tal situação revela a discriminação que ainda permeia a relação entre pessoas sem e com deficiência e a representação histórica que associa essa condição humana a incapacidade em compreender e decidir por si próprio.

Além disso, os participantes com deficiência visual ressaltaram a demora das companhias para responder às solicitações de assistência e a falta de pessoas qualificadas para atendimento nos aeroportos, conforme foi também evidenciado no estudo realizado por Silva (2016).

Esse estudo corroborou outros da literatura (PORIA; REICHEL; BRANDT, 2010; SMALL; DARCY; PACKER, 2012; SILVA, 2016) e mostrou que nas fases de pré-viagem, embarque e desembarque, os aeroportos analisados possuem barreiras relacionadas a fatores ambientais e sociais que geram limitaçóes para a realização de atividades e restrições a participação de passageiros com deficiência visual no transporte aéreo. Logo, melhorar as condiçóes e procedimentos relativos à acessibilidade poderá contribuir para que tais passageiros tenham uma experiência mais segura e independente nos aeroportos brasileiros. Para transformar as situações atuais é preciso cumprir as normas e resoluçôes já existentes na legislação nacional, mas também considerar a perspectiva e as atividades dos diversos atores sociais envolvidos com o transporte aéreo, o que está sendo estudado em outras pesquisas relacionadas ao Projeto

\section{Universalidade.}

Ressalta-se ainda que as discussôes e açôes relativas a deficiência, inclusão e acessibilidade requerem a colaboraçáo de diferentes setores e profissionais, entre os quais destacamos o terapeuta ocupacional que se preocupa em promover a saúde, o bem-estar e a participação das pessoas em diferentes contextos de vida. Na terapia ocupacional reconhece-se a interdependência da ocupação com o contexto (LECLAIR, 2010; DICKIE, 2011; TWINLEY, 2013), assim como, esse é reconhecido enquanto um dos fatores determinantes das experiências de funcionalidade, incapacidade e deficiência (ORGANIZAÇÃO..., 2008). Nessa perspectiva, o terapeuta ocupacional pode contribuir para avaliação das condiçôes dos aeroportos e aeronaves e dos procedimentos envolvidos no atendimento aos passageiros ao longo da viagem, como também na proposição de melhorias visando a inclusão de todos no contexto do transporte aéreo. Esse profissional poderá, por exemplo, a partir da análise das atividades e da compreensão das perspectivas e significados dos passageiros, identificar os determinantes ambientais e sociais que funcionam como barreiras que limitam a independência e autonomia dos diversos atores sociais e, consequentemente, restringem a participação desses nos diferentes contextos da vida cotidiana.

Esse estudo abordou especificamente experiências dos passageiros com deficiência, no entanto o transporte aéreo também possui trabalhadores com deficiência e as questóes relativas ao trabalho, saúde e inclusão compóem o domínio da terapia ocupacional desde o surgimento da profissão. Logo, intervir para melhorar a acessibilidade no transporte aéreo favorecerá o envolvimento das pessoas nas diversas ocupações e atividades que se realizam nesse contexto. Além disso, o conhecimento acumulado pelo terapeuta ocupacional favorece que esse possa dialogar com os diversos atores sociais no sentido de sensibilizá-los para o respeito à diversidade e, principalmente, implicá-los na construção de uma nova representação sobre a deficiência em uma perspectiva interacional com os fatores ambientais e sociais. Acreditamos ainda que a atuação do terapeuta ocupacional tem muito a contribuir para o envolvimento qualificado no fazer cotidiano, especialmente, à medida que esse profissional supera as fronteiras dos espaços tradicionais de cuidado e se aproxima dos contextos onde a vida acontece.

\section{Conclusão}

O estudo evidenciou problemas em relação à acessibilidade nos aeroportos analisados, os quais relacionam-se principalmente às condiçóes ambientais dos terminais, procedimentos ao longo do ciclo de viagem e atendimento aos passageiros. Foi verificado o descumprimento das normas e resoluções relativas à acessibilidade. Assim sendo, destaca-se que apesar de termos uma legislação que assegura o direito à participação nos diversos contextos de vida, seu cumprimento ainda é insuficiente, contribuindo para a manutenção de espaços que não são acessíveis para todos.

Espera-se que as avaliaçóes realizadas, juntamente com a compreensão das experiências dos passageiros com deficiência visual, possam contribuir para futuras intervençóes sobre as barreiras do espaço físico, inadequaçôes dos procedimentos aeroportuários e treinamento dos trabalhadores do transporte aéreo, visando a transformaçáo dos problemas apontados e a construção de espaços que favoreçam a plena participaçáo das pessoas com deficiência nas viagens aéreas. 


\section{Agradecimentos}

Os autores agradecem a colaboração dos participantes do estudo e o apoio da Agência Nacional de Aviação Civil e do Conselho Nacional de Desenvolvimento Científico e Tecnológico - CNPq (Processo 426491/2016-5).

\section{Referências}

AGÊNCIA NACIONAL DE AVIAÇÃO CIVIL - ANAC. Resolução nº 280, de 11 de julho de 2013. Dispóe sobre os procedimentos relativos a acessibilidade de passageiros com necessidade de assistência especial ao transporte aéreo e dá outras providências. Diário Oficial [da] República Federativa do Brasil, Poder Executivo, Brasília, DF, 16 jul. 2013. Disponível em: <www.anac.gov.br>. Acesso em: 12 jun. 2016.

AMIRALIAN, M. L. T. M. Compreendendo o cego: uma visão psicanalítica por meio de desenhos etários. São Paulo: Casa do Psicólogo, 1997.

AMIRALIAN, M. L. T. M. Sou cego ou enxergo? As questōes da baixa visão. Educar, Curitiba, n. 23, p. 15-28, 2004.

\section{ASSOCIAÇÃO BRASILEIRA DE NORMAS TÉCNICAS} - ABNT. NBR 9050: acessibilidade a edificaçôes, mobiliário, espaços e equipamentos urbanos. Rio de Janeiro, 2015.

BICAS, H. E. A. Acuidade visual: medidas e notaçóes: atualização continuada. Arquivos Brasileiros de Oftalmologia, São Paulo, v. 65, n. 3, p. 375-384, 2002.

BOURNE, R. R. A. et al. Magnitude, temporal trends, and projections of the global prevalence of blindness and distance and near vision impairment: a systematic review and meta-analysis. The Lancet, London, v. 5, n. 9, p. 888897, 2017. PMid:28779882.

BRASIL. Decreto n ${ }^{\circ}$ 5296, de 2 de dezembro de 2004. Dispóe sobre as Leis $\mathrm{n}^{\circ} 10.048$, de 8 de novembro de 2000, e n ${ }^{\circ} 10.098$, de 19 de dezembro de 2000 e dá outras providências. Diário Oficial [da] República Federativa do Brasil, Poder Executivo, Brasília, DF, 2 dez. 2004. Disponível em: <www.planalto.gov.br/ccivil_03/_ato2004-2006/2004/ decreto/d5296.htm>. Acesso em: 10 out. 2016.

BRASIL. Cartilha do Censo 2010: pessoas com deficiência. Brasília: SDH-PR/SNPD, 2012. Disponível em: <www. pessoacomdeficiencia.gov.br/app/sites/default/files/publicacoes/ cartilha-censo-2010-pessoas-com-deficienciareduzido. pdf>. Acesso em: 15 jun. 2016.

CHANG, F. C.; CHEN, C. F. Meeting the needs of disabled air passengers: factors that facilitate help from airlines and airports. Tourism Management, Hatfield, v. 33, n. 3, p. 529-536, 2012. http://dx.doi.org/10.1016/j. tourman.2011.06.002.

DARCY, S. (Dis)embodied air travel experiences: disability, discrimination and the effect of a discontinuous air travel chain. Journal of Hospitality and Tourism Management, Austrália, v. 19, n. 1, p. 1-11, 2012.

DICKIE, V. O que é ocupação? In: CREPEAU, E. B.; COHN, E. S.; SCHELL, B. A. B. Willard and Spackman: terapia ocupacional. Rio de Janeiro: Guanabara Koogan, 2011. p. 15-21.

DISCHINGER, M.; ELY, V. H. M. B.; PIARDI, S. M. D. G. Promovendo acessibilidade espacial nos edificios públicos: programa de acessibilidade às pessoas com deficiência ou mobilidade reduzida nas edificaçóes de uso público. Florianópolis: Ministério Público de Santa Catarina, 2012.

GOMES, L.; EMMEL, M. L. Mapeamento da acessibilidade em edifícios públicos de cultura. Cadernos de Terapia Ocupacional da UFSCar, São Carlos, v. 24, n. 3, p. 519-530, 2016. http://dx.doi.org/10.4322/0104-4931.ctoAO0741.

GUÉRIN, F. et al. Compreender o trabalho para transformá-lo: a prática da ergonomia. São Paulo: Edgard Blücher, 2001.

LECLAIR, L. L. Re-examining concepts of occupation and occupation-based models: occupational therapy and community development. Canadian Journal of Occupational Therapy, Ottowa, v. 77, n. 1, p. 15-21, 2010. http://dx.doi. org/10.2182/cjot.2010.77.1.3. PMid:20302185.

MINAYO, M. C. S. O desafio do conhecimento: pesquisa qualitativa em saúde. São Paulo: Hucitec, 2010.

ORGANIZAÇÃO DAS NAÇÓES UNIDAS - ONU. Convenção sobre os direitos das pessoas com deficiência. Nova Iorque, 2006.

ORGANIZAÇÃO MUNDIAL DA SAÚDE-OMS. CIF: Classificação Internacional de Funcionalidade, Incapacidade e Saúde. São Paulo: Editora USP, 2008.

ORGANIZAÇÃO MUNDIAL DA SAÚDE - OMS. Relatório mundial sobre a deficiência. Sáo Paulo: SEDPcD, 2011.

PORIA, Y.; REICHEL, A.; BRANDT, Y. The flight experiences of people with disabilities: an exploratory study. Journal of Travel Research, Austrália, v. 49, n. 2, p. 216-227, 2010. http://dx.doi.org/10.1177/0047287509336477.

SAMPAIO, R. F.; LUZ, M. T. Funcionalidade e incapacidade humana: explorando o escopo da classificação internacional da Organização Mundial da Saúde. Cadernos de Saúde Pública, Rio de Janeiro, v. 25, n. 3, p. 475-483, 2009. http://dx.doi.org/10.1590/S0102-311X2009000300002.

SILVA, T. N. R. Contradiçōes e descontinuidades nos sistemas de atividade do transporte aéreo brasileiro: restriçōes às viagens e as estratégias de passageiros com deficiência, idosos e obesos. 2016. 272 f. Tese (Doutorado em Engenharia de Produção) - Universidade Federal de São Carlos, São Paulo, 2016.

SILVA, T. N. R. et al. Passageiros com deficiência no transporte aéreo brasileiro: diferentes atores, perspectivas semelhantes. Gestão \& Produção, São Carlos, v. 24, n. 
1, p. 136-147, 2017. http://dx.doi.org/10.1590/0104530x1681-15.

SMALL, J.; DARCY, S.; PACKER, T. The embodied tourist experiences of people with vision impairment: management and implications beyond the visual gaze. Tourism Management, Hatfield, v. 33, n. 4, p. 941-950, 2012. http://dx.doi.org/10.1016/j. tourman.2011.09.015.

TWINLEY, R. The dark side of occupation: a concept for consideration. Australian Occupational Therapy Journal,
Melbourne, v. 60, n. 4, p. 301-303, 2013. http://dx.doi. org/10.1111/1440-1630.12026. PMid:23888980.

WORLD HEALTH ORGANIZATION - WHO.

Universal eye health: a global action plan 2014-2019.

Genebra, 2013. Disponível em: <http://www.who.int/ blindness/actionplan/en/>. Acesso em: 1 nov. 2018.

WORLD HEALTH ORGANIZATION - WHO. ICD11 for Mortality and Morbidity Statistics (ICD-11 MMS). Genebra, 2018. Disponível em: <https://icd.who.int/ browse11/1-m/en>. Acesso em: 1 nov. 2018.

\section{Contribuição dos Autores}

Talita Naiara Rossi da Silva e Nilton Luiz Menegon elaboraram e coordenaram o projeto. Ana Luisa Rodrigues Silva, Valéria Oliveira Caetano e Gabriela Almeida Silvestrini realizaram a coleta de dados e a análise dos dados em conjunto com Talita Naiara Rossi da Silva. Todos os autores contribuíram com a redação e revisão do texto e aprovaram a versão final do artigo.

\section{Notas}

${ }^{1}$ Refere-se acuidade visual como a função (visual) que exprime a capacidade discriminativa de formas; ou como o método com que se mede o reconhecimento da separação angular entre dois pontos no espaço (isto é, distância entre eles, relacionada ao primeiro ponto nodal do olho); ou da resoluçáo (visual) de suas respectivas imagens sobre a retina, relacionadas ao segundo ponto nodal do olho (BICAS, 2002). 